\title{
Caracterización Clínico-Epidemiológica de pacientes perinatalmente expuestos al VIH en el Hospital Nacional Mario Catarino Rivas
}

\author{
Clinical-Epidemiological Characterization of perinatally exposed \\ HIV patients. Mario Catarino Rivas National Hospital
}

\section{Dania Mabel Vidal Bautista*, Karen Erazo**, Patricia Chevez ${ }^{* * *}$}

\section{RESUMEN}

Antecedentes: En los países con escasos recursos, la infección por VIH infantil tiene dimensiones alarmantes. Más del $90 \%$ de los niños que viven con VIH en los países en desarrollo se infectaron por transmisión de madre a hijo durante el embarazo, parto o lactancia. Con el fin de reducir el número de niños infectados por el VIH, se ha enfatizado en los programas de prevención de la transmisión vertical, encontrándose una reducción de la transmisión del virus, actualmente menos del $1 \%$ en niños de bajo riesgo. Objetivo: Caracterizar clínica y epidemiológicamente a los pacientes perinatalmente expuestos al VIH atendidos en el Hospital Nacional Mario Catarino Rivas enero 2018 - junio del 2019. Pacientes y Métodos: Estudio cuantitativo, observacional, descriptivo; se realizó la revisión de 42 expedientes clínicos, se aplicó un cuestionario de 23 preguntas abiertas y cerradas, evaluando variables clínicas y epidemiológicas. Resultados: el 85\% de las madres conocían el diagnostico de ser VIH positivo, 66\% diagnosticadas previo al embarazo, $80 \%$ en tratamiento con ARV, $26 \%$ con carga viral no detectable, $78 \%$ finalizo su embarazo vía cesárea, $53 \%$ fueron categorizados como alto riesgo, $85 \%$ recibió terapia ARV por 4 semanas, incidencia de VIH fue de 4.7\%, 2 de los 42 pacientes, $19 \%$ están perdidos en seguimiento, $88 \%$ recibió profilaxis con TMP-SMX.Conclusiones: El diagnóstico precoz de VIH en la infancia mediante la realización de pruebas vi

* Médico Residente tercer año de Pediatría, UNAH-VS. ** Médico Pediatra, Servicio de Atención Integral, HNMCR. *** Médico Pediatra, Servicio de Atención Integral, HNMCR. Dirigir correspondencia a: damavibau_723@hotmail.com Recibido: 20 de Diciembre 2019 Aprovado:15 de marzo 2020 favorece al inicio temprano de tratamiento antirretroviral con un pronóstico de vida más favorable.

PALABRAS CLAVE: VIH, transmisión vertical, ARV.

ABSTRACT

Background: In countries with limited resources, childhood HIV infection has alarming dimensions. More than $90 \%$ of children living with HIV in developing countries were infected by transmission from mother to child during pregnancy, during childbirth or during breastfeeding. In order to reduce the number of HIV-infected children, emphasis has been placed on prevention programs for vertical transmission. Objective: To characterize clinically and epidemiologically the perinatally exposed HIV patients treated at the Mario Catarino Rivas National Hospital between January 2018 - June 2019. Patients and Methods: Quantitative, observational, descriptive study; The review of 42 clinical records was carried out, a questionnaire of 23 open and closed questions was applied, evaluating clinical and epidemiological variables. Results: $85 \%$ of the mothers knew the diagnosis of being HIV positive, 66\% diagnosed before pregnancy , $80 \%$ on ARV treatment, $26 \%$ with undetectable viral load, $78 \%$ ended their pregnancy via caesarean section, 53\% were categorized as high risk, $85 \%$ received ARV therapy for 4 weeks, HIV incidence was $4.7 \%, 2$ of 42 patients, $85 \%$ of patients did not receive breastfeeding, 19\% are lost to follow-up, $88 \%$ received prophylaxis with TMP-SMX. Conclusions: The main protective factor in perinatal transmission of HIV is maternal viral load not detectable.

KEYWORDS: HIV, vertical transmission, ARV. 


\section{INTRODUCCIÓN}

Según datos de ONUSIDA, a finales del año 2017, a nivel mundial, se estimaban más de 36.9 millones de personas infectadas por el VIH. Se calcula que, en todo el mundo, 3,3 millones de menores de 15 años viven con el VIH y que, en el año 2012, han fallecido 210.000 pacientes de este grupo etario. En el 2012, la tasa de incidencia anual de VIH se estimó en 2,3 millones. Aproximadamente, el $11 \%$ de estas nuevas infecciones (260.000 casos) han ocurrido en niños menores de 15 años. Desde el año 2001, ha disminuido el número de nuevas infecciones en un 33\%, las muertes relacionadas con el SIDA en un $29 \%$, las nuevas infecciones en niños en un 52\%, y ha aumentado en un $40 \%$ el acceso a los antirretrovirales. En países desarrollados, los nuevos casos de infección VIH pediátricos son casi excepcionales, gracias a los programas de prevención de la transmisión vertical (PPTV). ${ }^{1-2}$

Más del 90\% de los niños que viven con el VIH en los países en desarrollo se infectaron por transmisión de madre a hijo durante el embarazo, durante el parto o durante la lactancia. Con el fin de reducir el número de niños infectados por el VIH, se ha enfatizado en los PPTV. Aunque estos programas están muy extendidos a nivel mundial, sólo una parte de las mujeres infectadas por el VIH en las áreas con menos recursos tienen acceso a ellos, oscilando su cobertura entre un $75 \%$ y un $15 \%$, según los distintos países..$^{3-4}$

\section{PACIENTES Y MÉTODOS}

Se realizó un estudio cuantitativo, observacional y descriptivo en el Servicio de Atención Integral del Hospital Nacional Mario Catarino Rivas de San Pedro Sula, Honduras. Se identificaron los pacientes perinatalmente expuestos al VIH desde enero del 2018 a junio del 2019, obteniéndose un total de 42 pacientes, procediéndose a revisión de los expedientes clínicos, se aplicó un cuestionario de 23 preguntas abiertas y cerradas.

El Criterios de Inclusión fueron: Pacientes de edad pediátrica sin rangos de edad que han sido expuestos perinatalmente al $\mathrm{VIH}$, nacidos o no en el HNMCR que están en control y seguimien- to en el SAI. El método de muestreo fue aleatorizado simple. Se realizo la tabulación de los datos primeramente en una base de datos de Microsoft Excel 2013. Se procedió a ingresar los datos al programa estadístico EPIInfo versión 7.2.2.16. Se analizó las variables categóricas, obteniéndose frecuencias expresadas en porcentajes.

\section{RESULTADOS}

Se estudiaron 42 pacientes perinatalmente expuestos al VIH en el Hospital Nacional Mario Catarino Rivas entre enero 2018 - junio $2019 \mathrm{cu}$ yas edades eran variables entre días hasta los 18 meses. De los 42 pacientes documentados en 18 meses un $52.4 \%$ fueron hombres solo un $47.6 \%$ mujeres. El 45\% residen en San Pedro Sula, el resto en diferentes municipios aledaños. El 90\% de los 42 pacientes perinatalmente expuestos al VIH tuvieron una edad gestacional entre las $37 \mathrm{y}$ 42 semanas de gestación, solo 9,52\% eran prematuros y no se registró ningún paciente postérmino. (ver gráfico $\mathrm{N}^{\circ} 1$ )

Gráfico $N^{\circ}$ 1. Edad Gestacional al Nacimiento de los pacientes perinatalmente expuestos al $\mathrm{VIH}$ atendidos en el Hospital Nacional Mario Catarino Rivas entre enero 2018-junio 2019.

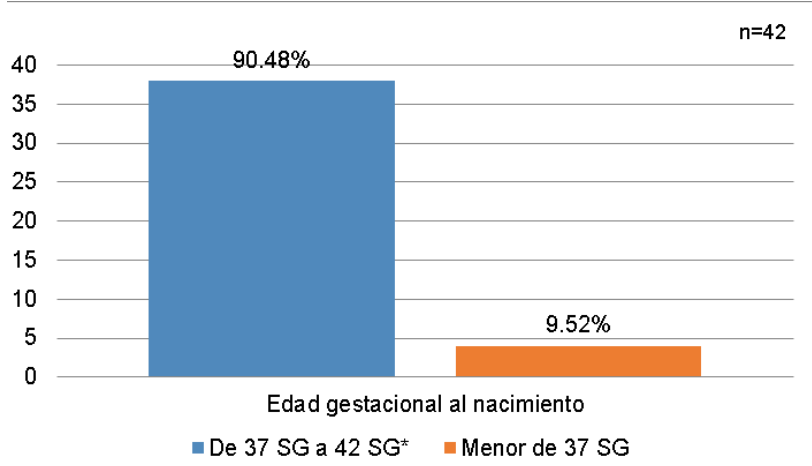

Fuente: Instrumento de recolección de datos.

Datos Maternos: de las 42 madres estudiadas un $85 \%$ conocía el diagnostico de ser VIH positivo previo al parto, solo un $15 \%$ se diagnosticó posterior al mismo, 66\% antes del embarazo, 19\% durante el embarazo y un $14 \%$ en su puerperio. (ver gráfico $\mathrm{N}^{\circ} 2$ ) El $80.95 \%$ recibieron terapia 
antirretroviral con Atripla (efavirenz, emtricitabina y tenofovir), 8 de ellas no tomaron ningún $\mathrm{ARV}$, dos por la poca adherencia al tratamiento y 6 diagnosticadas en el puerperio. La carga viral materna un $26 \%$ fue no detectable, $16 \%$ tuvieron más de 1000 copias y 19\% se desconocía. El 78\% finalizo el embarazo vía cesárea.

Gráfico N² 2. ¿Cuándo se realizó el diagnóstico de VIH en la madre de los pacientes perinatalmente expuestos al VIH atendidos en el Hospital Nacional Mario Catarino Rivas entre enero 2018-junio 2019?

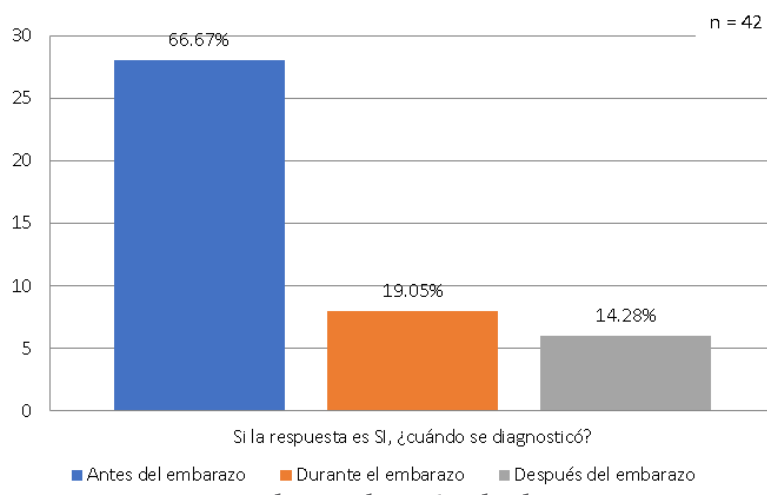

Fuente: Instrumento de recolección de datos

Datos pediátricos: El 83\% (n:42) de los pacientes tuvo un adecuado peso a su nacimiento, $88 \%$ fueron hospitalizados en su mayoría por ser hijos de madre VIH positiva, con una media de estancia hospitalaria de dos días, según su categoría de riesgo 52\% fueron clasificados como alto riesgo. (ver grafica $\mathrm{N}^{\circ} 3$ )

Gráfico $N^{\circ}$ 3. Categoría del Riesgo por infección por VIH de los pacientes perinatalmente expuestos al VIH atendidos en el Hospital Nacional Mario Catarino Rivas entre enero 2018 Junio 2019.

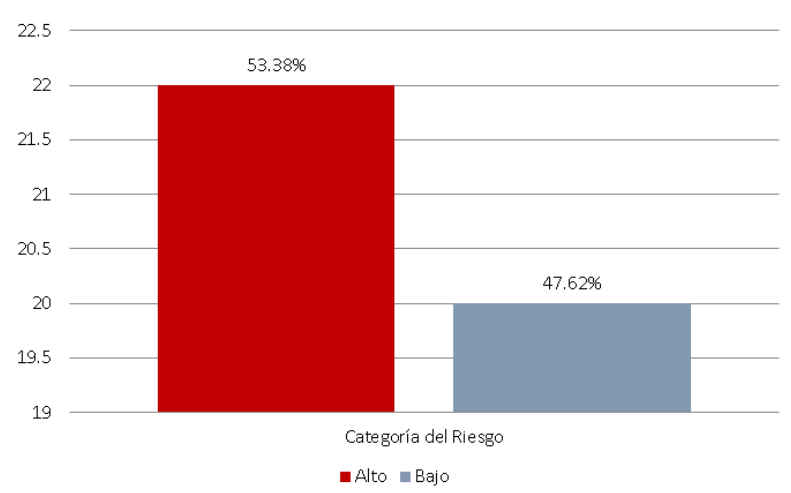

Fuente: Instrumento de recolección de datos. 
La mayoría de los pacientes perinatalmente expuesto al VIH recibió terapia ARV el 86\% durante 4 semanas, el resto se captaron tarde. De los 22 pacientes categorizados como alto riesgo a los cuales se les solicito PCR a las 48 horas, $72 \%$ fueron negativos, solo un paciente fue positivo y en un $22.7 \%$ no se realizó. (ver grafica $\mathrm{N}^{\circ} 4$ ). El $88 \%$ (n:42) de los resultados de PCR al mes de vida fue negativo, se captó un niño con PCR positivo el cual aún está pendiente su segundo PCR para confirmar el diagnostico. De los 31 pacientes que son mayores de 6 meses, en un $80.65 \%$ tuvieron PCR negativo, en un $12.9 \%$ no se realizó porque los pacientes están perdidos en seguimiento. El $85 \%$ (n:42) no recibió lactancia materna, el $85 \%$ tiene un estado nutricional adecuado, $80 \%$ esquema de vacunación completo para la edad, el 73\% de los RPR son no reactivos, el resto se desconocía, $81 \%$ están en seguimiento en el SAI. El 88\% recibió profilaxis de TMP-SMX. De los 42 pacientes perinatalmente expuestos al VIH en seguimiento en el SAI en los 18 meses se obtuvieron dos PCR positivo, con una incidencia de $4.76 \%$, pendiente de confirmarse el segundo PCR. (Ver grafica $\mathrm{N}^{\circ}$ 5)

Gráfico N ${ }^{\circ}$ 4. Resultado de PCR de Recién Nacido a las 48 horas perinatalmente expuestos al VIH atendidos en el Hospital Nacional Mario Catarino Rivas entre enero 2018 - Junio 2019.

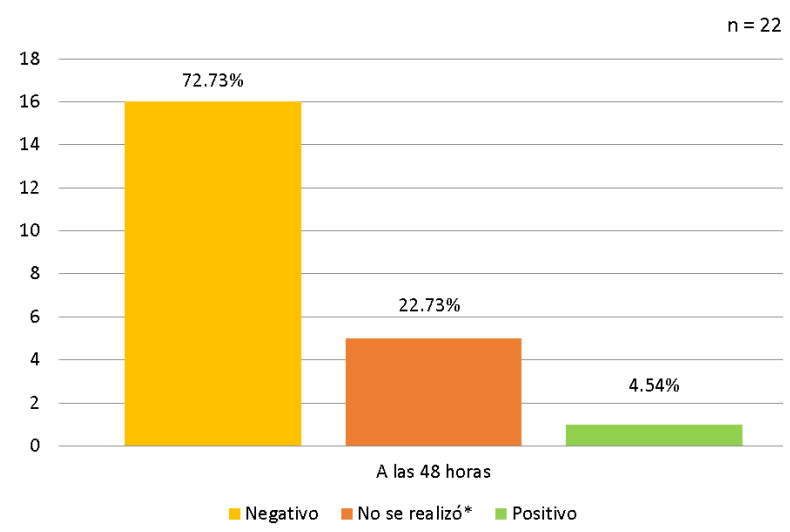

Fuente: Instrumento de recolección de datos
Gráfico $N^{\circ} 4$. Resultado de PCR de Recién Nacido a las 48 horas perinatalmente expuestos al VIH atendidos en el Hospital Nacional Mario Catarino Rivas entre enero 2018 - Junio 2019.

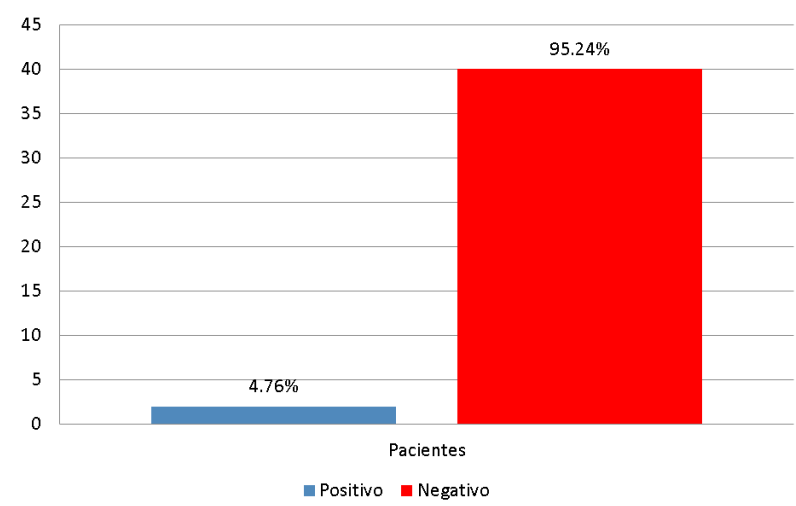

Fuente: Instrumento de recolección de datos

\section{DISCUSIÓN}

Desde la introducción de los antirretrovirales (ARV) para prevención de la transmisión del VIH de la madre a hijo/hija, la tasa de incidencia ha disminuido a cifras tan bajas como 1 - 2\% según la OMS. Lo cual es similar a lo encontrado en Honduras en este estudio en el cual se estimó una tasa de transmisión vertical del VIH del $4.7 \%$ en los pacientes atendidos en el Hospital Nacional Mario Catarino Rivas entre enero 2018 - junio 2019. Incidencia que ha aumentado en un $2 \%$ con relación a estudio realizada en el 2009 en este mismo centro hospitalario encontrado una tasa de transmisión vertical de $2.7 \%{ }^{4}$ Tasas similares se encontraron en Nicaragua donde se estimó una incidencia del $2.8 \%$ en los pacientes expuesto perinatalmente al VIH, atendidos en el Hospital Alemán Nicaragüense, del 1 de enero de 2013 y el 31 de diciembre del 2016. ${ }^{7}$ En este estudio se encontró la mayoría de los pacientes perinatalmente expuestos al VIH viven en áreas Urbanas y no hay diferencias significativas en cuanto al sexo, similar a lo encontrado en nicaragua donde el $75 \%$ procedían de áreas urbanas. ${ }^{7-8}$ El 90\% de los pacientes en seguimiento fueron recién nacidos a término, semejándose a lo en- 
contrado en España también fueron a término. El 85\% de las madres en este estudio tenía conocimiento de ser VIH positivos, $15 \%$ fueron diagnosticadas en el puerperio. El 80\% recibió terapia ARV, un porcentaje bajo en comparación al $97 \%$ encontrado en el estudio Nicaragüense realizado en Hospital Alemán 2013-2016 y en Perú donde 92\% recibió ARV durante el embarazo.9-10 La carga viral materna encontradas en las madres Hondureñas en este estudio fue $26 \%$ no detectable y también un 26\% tuvieron menos de 1000 copias, 28\% más de 1000 copias, en Perú en el estudio realizado en recién nacidos de madres VIH positivas del Hospital Carlos Lanfranco La Hoz en el periodo 2014-2017 las madres reportaron menos de 1000 copias en un 60\%.10 La vía de finalización del embarazo en este estudio fue por cesárea en un $78 \%$, en un $26 \%$ hubo RPM, $14 \%$ de las madres les dieron lactancia materna a sus bebes, principalmente en aquellas madres cuyo diagnostico se realizó en el puerperio, no teniendo un adecuado control prenatal. Comparado con el Hospital Alemán Nicaragüense el $97 \%$ de los embarazos finalizaron vía cesárea, 14\% de las madres tuvo RPM y ninguna del estudio le dio lactancia materna a sus hijos. ${ }^{7}$ El $88 \%$ de los pacientes perinatalmente expuesto al VIH fueron hospitalizados a su nacimiento, $73 \%$ fueron por ser hijos de madres VIH positivo sin tener otras comorbilidades, de los 42 pacientes el $52 \%$ fue categorizado con alto riesgo. En relación con el estudio realizado en Nicaragua el $83 \%$ fueron categorizados como alto riesgo, obteniendo un porcentaje significativamente menos en este estudio. ${ }^{7}$ Se le realizo PCR a las 48 horas en el $77 \%$ de los pacientes, en un $23 \%$ fueron captados después de esa edad por lo que no se le realizo, $88 \%$ presento PCR negativos al mes de vida, 31 pacientes tienen una edad mayor de 6 meses obteniéndose un PCR negativo en un $80 \%, 4$ pacientes se les realizo el VIH a los 18 meses, el 75\% fueron negativos, $85 \%$ recibió profilaxis con ARV durante 4 semanas, $40 \%$ con triple ARV (AZT, 3TC y NVP), $42 \%$ con AZT y 3TC. En Quito en el 2017 en un estudio realizado en el hospital de Baca Ortiz de profilaxis antirretroviral en niños expuestos per- inatales al virus de inmunodeficiencia humana 96\% de sus niños recibieron terapia con ARV.8 El presente estudio confirma el éxito de las acciones de intervención del Programa de prevención de Transmisión Materno infantil del VIH, el cual se cumple en más del 95\% de sus estándares, contribuyendo con esto en mantener a Honduras en la categoría de Cerca de la meta de eliminación de la Tasa de transmisión vertical de VIH (tasa calculada $>2 \%$ y $\leq 5 \%$ ) (OPS/OMS 2014).11,12,14

Por lo tanto, el principal reto es lograr la captación de las embarazadas con VIH y de sus hijos oportunamente para ingresarlas al programa.13,15

\section{REFERENCIAS BIBIOGRÁFICAS}

1. Honduras [Internet]. Unaids.org. 2018 [cited2July2018]. Availablefrom:http://www.unaids. org/es/regionscountries/countries/honduras 2. Pediatric HIV [Internet]. Unaids.org. 2018 [cited 2 July 2018]. Available from: http:// www.unaids.org/es/keywords/pediatric-hiv 3. Reducción del número de niños que nacen con el VIH [Internet]. Unaids. org. 2018 [cited 2 July 2018]. Available from: http://www.unaids.org/es/topic/children 4. Erazo, Karen, Experiencia de la Transmisión Vertical del Virus VIH en el Hospital Dr. Mario Catarino Rivas, San Pedro Sula. 2009 5. Cohn J, Whitehouse K, Tuttle J, Lueck K, Tran T. Pediatrics HIV testing beyond the context of prevention of mother-to-child transmission: a systematic review and meta-analysis. The Lancet HIV. 2016;3(10): e473-e481. 6. Evans C, Jones C, Prendergast A. HIV-exposed, uninfected infants: new global challenges in the era of pediatrics HIV elimination. The Lancet Infectious Diseases. 2016;16(6): e92-e107. 7. Morales Miriam. Abordaje y resultado clínico de la prevención de la transmisión vertical del VIH en niños y niñas de 0 a 18 meses atendidos en el Hospital Alemán Nicaragüense entre el 1 de enero de 2013 y el 31 de diciembre del 2016. Tesis doctoral. Febrero 2017. 8. López Cristian. Profilaxis antirretroviral en niños expuestos perinatales al virus de 
inmunodeficiencia humana Hospital Baca Ortiz 2010 - 2015. Tesis doctoral. Quito. Febrero 2017

9. Severiano, Rubén. Prevalencia de VIH en recién nacidos de madres VIH positivas del Hospital Carlos Lanfranco La Hoz en el periodo 2014-2017. Tesis doctoral. Lima, Perú. 2018. 10. Prieto, Luis Manuel. Características y evolución de los programas de prevención de la transmisión vertical de VIH en entornos diferentes. Tesis doctoral. Madrid. Octubre 2017. 11. Penazzato M, Revill P, Prendergast A, Collins I, Walker S, Elyanu P et al. Early infant diagnosis of HIV infection in low-income and middle-income countries: does one size fit all? The Lancet Infectious Diseases. 2014;14(7):650-655. 12. Manual de Atención Integral a la embarazada para la prevención de la transmisión del VIH de madre a hijo o hija, Departamento VIH/SIDA, Secretaria de Salud Honduras, diciembre 2013. 13. Hurst S, Appelgren K, Kourtis A. Prevention of mother-to-child transmission of HIV Type 1: the role of neonatal and infant prophylaxis. Expert Review of Anti-infective Therapy. 2015;13(2):169-181. 14. Johnson E, Chakraborty R. HIV1 at the placenta. Current Opinion in Infectious Diseases. 2016;29(3):248-255. 15. Sibiude J, Warszawski J, Blanche S. Tolerance of the newborn to antiretroviral drug exposurein utero. Expert Opinion on Drug Safety. 2015;14(5):643-654. 